\title{
In Response to: "Single Versus Multiple Hyperbaric Sessions for Carbon Monoxide Poisoning in a Murine Model"
}

\author{
Leah S. Croll ${ }^{1} \cdot$ Rachel S. Wightman ${ }^{1} \cdot$ Robert S. Hoffman ${ }^{1}$
}

Received: 7 September 2016 / Accepted: 21 September 2016 / Published online: 4 October 2016

(C) American College of Medical Toxicology 2016

While hyperbaric oxygen (HBO) is the best-studied treatment for prevention of the delayed neurologic sequelae (DNS) in carbon monoxide (CO) poisoning, its effectiveness is unclear. Human and animal studies demonstrate contradictory results, and several reviews highlight significant methodological weaknesses in the existing literature $[1,2]$. Thus, we read with interest the recent article by Carstairs et al. [3] regarding single versus multiple $\mathrm{HBO}$ sessions in a murine model of $\mathrm{CO}$ poisoning. The authors sought to answer a compelling and pertinent question with a promising study design. However, we are concerned that the model used for DNS was not sufficiently reliable to adequately address their question.

No significant difference was found in the outcome measures between the group of mice that were CO-poisoned and received no treatment and the control group of mice that were not poisoned at all. Simply put, this study failed to induce DNS in CO-poisoned mice. Thus, since the chosen outcome measure does not accurately reflect the disease process, any results are consequently impossible to interpret. Although the authors attribute this shortcoming to wide variations between animals and suggest that the study suffers from a small sample

Leah S. Croll

leah.croll@med.nyu.edu

1 New York University School of Medicine, 550 1st Avenue, New York, NY 10016, USA size problem, they present a curious power analysis that should have taken this variability into consideration.

Unfortunately, it is unclear whether passive avoidance testing is an appropriate model or that the mice were adequately trained $[4,5]$ or whether there were other flaws in the study design or implementation. Regardless of the cause, there are no conclusions that can be drawn from their data.

\section{Compliance with Ethical Standards}

Conflicts of Interest None.

Sources of Funding None.

\section{References}

1. Buckley NA, Isbister GK, Stokes B, Juurlink DN. Hyperbaric oxygen for carbon monoxide poisoning: a systematic review and critical analysis of the evidence. Toxicol Rev. 2005;24:75-92.

2. Buckley NA, Juurlink DN, Isbister G, Bennett MH, Lavonas EJ. Hyperbaric oxygen for carbon monoxide poisoning. Cochrane Database Syst Rev. 2011;4:CD002041.

3. Carstairs SD, Miller AD, Minns AB, Duchnick J, Riffenburgh RH, Clark RF, et al. Single versus multiple hyperbaric sessions for carbon monoxide poisoning in a murine model. J Med Toxicol. 2016. doi:10.1007/s13181-016-0573-5.

4. Gilmer B, Kilkenny J, Tomaszewski C, Watts JA. Hyperbaric oxygen does not prevent neurologic sequelae after carbon monoxide poisoning. Acad Emerg Med. 2002;9:1-8.

5. Hiramatsu M, Satoh H, Kameyama T, Nabeshima T. Nootropic effect of nicotine on carbon monoxide (CO)-induced delayed amnesia in mice. Psychopharmacology. 1994;116:33-9. 